\begin{tabular}{|c|c|c|}
\hline$\xi$ & $\begin{array}{c}\text { International Journal of Current Research } \\
\text { and Academic Review }\end{array}$ & $=$ \\
\hline $\begin{array}{l}\text { EXCELLENT } \\
\text { PUBLISHERS }\end{array}$ & $\begin{array}{l}\text { ISSN: 2347-3215 (Online) Volume } 7 \text { Number } 3 \text { (March-2019) } \\
\text { Journal homepage: http://www.ijcrar.com }\end{array}$ & \\
\hline
\end{tabular}

doi: https://doi.org/10.20546/ijcrar.2019.703.006

\title{
A Comparative Study for Efficacy of Levobupivacaine and Ropivacaine on Labor Analgesia
}

\author{
Meenal Jain $^{1 *}$, Richa Singh ${ }^{2}$ and Archana Agarwal ${ }^{2}$ \\ ${ }^{\text {I}}$ Obstetrics and Gynaecology, SNMC, Agra, India \\ ${ }^{2}$ Department of Anaesthesia, SNMC, Agra, India \\ *Corresponding author
}

\begin{abstract}
Bupivacaine has been used for the purpose of epidural analgesia for many years but studies suggest that it produces higher degree of motor blockage and is cardiotoxic in higher doses, so a number of new drugs are being introduced. Based on their lower toxicity and less intense motor blockage levorotatory form of Bupivacaine, levobupivacaine and ropivacaine (an amide local anesthetic) have many advantages over Bupivacaine for the purpose of labour analgesia. So this study was planned to perform a comparison between efficacy and safety of levobupivacaine and ropivacaine for labour analgesia and it's effect on maternal and perinatal outcome. 100 parturients with 37-41wks pregnancy in active labour with no obstetrical and medical complications requesting for painless labour were included in the study. They were randomly divided into two groups of 50 participants each. Group A received levobupivacaine and group B was given ropivacaine. After the initial dose epidural top ups were given on patient demand. The parameters recorded were for analgesia, anaesthesia, motor, maternal, fetal, perinatal as well as assessment of progress of labour. The mean time, mean dose and mean number of boluses required were not statically different in the two groups. The motor blockage and degree of pain relief was also comparable in both the groups. Also the progress of labour and perinatal outcome were not stastically different in the two groups. Both drugs were safe. Both levobupivacaine and ropivacaine have equal efficacy and safety for labour analgesia and both of them have comparable maternal and perinatal outcome.
\end{abstract}

\section{Introduction}

Labour pain remains the most severe pain experienced by women in her lifetime. Thus, it becomes indispensable to make the painful process of labor as painless and pleasant as possible.

Among all the methods, the safest and most effective pain relief during labour and at the time of delivery is best accomplished by the skillful use of lumbar epidural analgesia.

\section{Article Info}

Accepted: 04 February 2019

Available Online: 20 March 2019

\section{Keywords}

Levobupivacaine,

Ropivacaine, Labour pain. 
Bupivacaine has been used for the purpose of epidural analgesia for many years because of its long duration of action, limited placental transfer and minimal neonatal effects, but many studies suggest that bupivacaine produces higher degree of motor blockage and is cardio toxic in higher doses, so a number of new drugs are being introduced now a day.

Based on their lower toxicity and less intense motor blockage, levorotatory form of bupivacaine, levobupivacaine and ropivacaine (an amide local anaesthetic produced in pure form) have many advantages over bupivacaine for the purpose of labour analgesia. $^{(2)}$

So, our study was planned to perform a study between efficacy and safety of levobupivacaine and ropivacaine for labour analgesia and its effect on maternal and perinatal outcome.

\section{Materials and Methods}

After obtaining a written informed consent and Hospital ethics committee approval, this prospective double blind randomised controlled study was conducted in the Department of Obstetrics and Gynaecology, S.N. Medical College, Agra.

100 parturients with $37-41$ Week of pregnancy in active labour with no obstetrical and medical complications, requesting for painless labour were included in the study.

Criteria for selection of cases:

Patient demand.

Both primipara and multipara patients.

Singleton pregnancy with vertex presentation.

Patients with adequate pelvis.

Patients in active phase of labour i.e. dilatation of cervix is $>3 \mathrm{cmand}$ rate of dilatation of cervix is $1 \mathrm{~cm}$ per hour in primigravida and $1.5 \mathrm{~cm}$ in multigravida.

Patients with stable fetal parameters.

Criteria for exclusion for cases:

Patient refusal.

Drug sensitivity.

Pregnancy complicated with obstetrical conditions.
a. Multiple pregnancy.
b. Malpresentation.
c. Antepartum haemorrhage.
d. Fetal congenital abnormality.
e. Previous cesarean section.

f. Cephalo-pelvic Disproportion.

2. Pregnancy complicated with any medical conditions

a. Pregnancy induced hypertension.

b. Eclampsia.

c. Gestational diabetes mellitus.

d. Local infection

e. Septicemia

3. Anatomical abnormality of maternal spine.

4. Maternal morbid obesity.

The subjects were allocated into groups i.e. group A and group $\mathrm{B}$, each comprising 50 participants by various method of random allocation. Those in group A received $10 \mathrm{ml}$ of $0.125 \%$ of levobupivacaine and those in group $\mathrm{B}$ receive $10 \mathrm{ml}$ of $0.125 \%$ of ropivacaine.

The age, weight, height, parity, and gestational age were recorded. A quick thorough clinical examination was done. An epidural catheter was placed and secured in the L2 and L4 intervertebral space.

The participants were given an initial epidural injection of one of the two anesthetics by random allocation. Those in group A received $10 \mathrm{ml}$ of $0.125 \%$ levobupivacaine and those in group B received $10 \mathrm{ml}$ of $0.125 \%$ ropivacaine. the study period was taken from initial epidural injection till delivery of the baby. The time from first epidural injection to the first painless contraction was taken as onset of epidural analgesia.The duration of epidural analgesia is defined as duration between first epidural injection and request for epidural top-ups. In both the groups, epidural top-ups were given on patient demand with no background infusion.

After the administration of proper anaesthesia to all the participants, various parameters were studied and recorded for analgesia, anaesthesia, motor, maternal, fetal, perinatal as well as assessment of progress of labour. Assessment of pain relief was carried before the epidural injection and then at 10 minute interval for first 30 minutes and at hourly interval thereafter by VISUAL ANALOGUE PAIN SCORE.

The highest dermatomal level of sensory block was assessed using loss of pinprick sensation in the mid clavicular line before administration of epidural analgesia, then at 5,10,20,30, $45 \& 60$ minutes in every 30 minutes thereafter until delivery. Motor blockage was assessed using a Modified Bromage Scale.

Assessment of progress of labour was carried out by studying -

the rate of cervical dilatation 
number and duration of uterine contractions, total duration of stages of labour among primiparous as well as multiparous women belonging to both the groups,

time duration between admission and delivery, use of assisted vaginal delivery methods, rate of conversion to cesarean section and incidence of post partum hemorrhage.

Maternal assessment was done by recording maternal vitals i.e. blood pressure, pulse rate, temperature and respiratory rate at the time of admission and every 2 hourly thereafter. Any other side effects such as nausea, vomiting, pruritis, back ache and shivering were recorded. Maternal satisfaction with labour analgesia was also evaluated by parturients after delivery.

Fetal assessment was done by recording Fetal Heart Rate (FHR) by auscultation after regular interval of time i.e. after every 15 minutes. Foetal cardiotocogram (CTG) were recorded continuously throughout the study.

any FHR abnormalities identified were recorded.

Perinatal outcome was recorded by -

1. Meconium Stained Liquor.

2. APGAR score.

3. Birth Weight.

4. Perinatal mortality.

5. NICU admission.

\section{Results and Discussions}

The cases fulfilling all the essential pre-requisites were studied and following observations made. The chi square test was applied and $\mathrm{p}$ value $>0.05$ was considered to be significant. Table 1 shows the demographic profile. According to this, there was no statistically significant difference in the mean age, mean BMI and mean gestational age of the subject belonging to the two groups. Majority of patients were primigravida in both the groups.

Fig.1 shows distribution of cases among the two groups according to the Bishop's Score at the time of admission. The Pie Charts show that maximum patients in both the groups had favourable Bishops score (>6)at the time of admission. Table 2 shows distribution of cases according to mean time required for the onset of analgesia after first dose of anaesthetic agent, mean number of boluses required and mean dose of anaesthetic required.
The mean time required for onset of analgesia after first dose of anaesthetic required in both the groups was almost same for the purpose of labouranalgesia. The mean dose required and the mean numbers of boluses of the anaesthetic required are also not statistically different in both the groups. Table 3 depicts distribution of cases according to the duration of various stages of labour among primiparas and multiparas in the two groups and we can see that there was no significant difference among various stages of labour in primiparas as well as multiparas belonging to the two groups. The admission delivery interval in both the groups is also not significantly different.

Figure 2 shows the motor blockage as assessed by the modified Bromage score in both the groups. The $\mathrm{p}$ value is 0.09 , hence, it can be concluded that there is no statically significant difference in the motor blockage as produced by the two groups. Table 4 shows distribution of cases among the two groups on the basis of mode of delivery. $p$ value for the mode of delivery is not statistically significant. Thus, there was no difference in the mode of delivery among the two groups. Majority of the cases in both the groups delivered vaginally. Cesarean section had to be done for the cases with a nonreassuring fetal heart rate or non progression of labour.

Table 5 shows distribution of cases according to the parameters assessing perinatal outcome, neonatal birth weight and mean APGAR score at birth.

$\mathrm{p}$ value for mean neonatal birth wt and Mean APGAR score is0.33 and 0.70 indicating that there is no statistically significant differences in these parameters among the two groups. NICU admission was 3 and 4 respectively in both the groups for observation there was no perinatal mortality. Fig. 3 shows distribution of cases among the two groups on the basis of maternal satisfaction and it is clear that majority of cases had a good to excellent level of satisfaction in pain relief. Fig. 4 depicts distribution of cases among the two groups on the basis of degree of pain relief (VAPS). The $p$ value for pain relief as detected by VAPS is 0.96 signifying that there are no statistically significant differences between the two groups in terms of pain relief. In Fig.5 distribution of cases on the basis of maternal side effects among the two groups is shown. Common side effects seen were nausea, vomiting, pruritis and hypertension which were managed symptomatically. No statistically significant difference was detected in terms of side effects among the two groups. Thus both drugs are safe. 
Table.1

\begin{tabular}{|c|c|c|}
\hline Distribution & \multicolumn{2}{|c|}{ Case according to demographic profile } \\
\hline & GROUP A & GROUP B \\
\hline Mean age (years) & $23.6 \pm 2.34$ & $24.2 \pm 1.06$ \\
\hline Mean BMI & $26.2 \pm 1.05$ & $25.9 \pm 2.12$ \\
\hline Mean G A & $37.4 \pm 1.01$ & $37.9 \pm 0.06$ \\
\hline
\end{tabular}

Table.2 Distribution of cases according to parameters of analgesia

\begin{tabular}{|l|c|c|c|}
\hline & Group A & Group B & p value \\
\hline $\begin{array}{l}\text { Mean time required for the onset of } \\
\text { analgesia (mins.) }\end{array}$ & $15.5 \pm 4.54$ & $16.3 \pm 4.61$ & 0.51 \\
\hline Mean number of boluses required & $2 \pm 0.78$ & $2.2 \pm 0.73$ & 0.77 \\
\hline Mean dose of anaesthetic required(mg) & 38 & 40 & 0.77 \\
\hline
\end{tabular}

Table.3 Distribution of cases according to duration of stages of labour in both the groups

\begin{tabular}{|l|c|c|c|c|}
\hline & \multicolumn{2}{|c|}{ Primiparas } & \multicolumn{2}{c|}{ Multiparas } \\
\hline & Group A & Group B & Group A & Group B \\
\hline Stage 1 (hrs) & $8.74 \pm 0.85$ & $8.5 \pm 1.187$ & $4.53 \pm 0.85$ & $4.94 \pm 1.75$ \\
\hline Stage 2 (mins.) & $48 \pm 59.1$ & $42.42 \pm 6.27$ & $11.66 \pm 9.1$ & $14.70 \pm 4.49$ \\
\hline Stage 3 (mins.) & $5.73 \pm 1.79$ & $7.06 \pm 1.95$ & $6.66 \pm 1.79$ & $6.94 \pm 01.25$ \\
\hline
\end{tabular}

Table.4 Distribution of cases according to mode of delivery

\begin{tabular}{|l|l|l|}
\hline \multicolumn{1}{|c|}{ Mode of delivery } & \multicolumn{1}{c|}{ Group A } & \multicolumn{1}{c|}{ Group B } \\
\hline Vaginal & 46 & 45 \\
\hline Instrumental & 01 & 00 \\
\hline Cesarean Section & 03 & 05 \\
\hline p value & 0.46 & \\
\hline
\end{tabular}

Table.5 Distribution of cases according to perinatal outcome

\begin{tabular}{|l|c|c|c|}
\hline & GROUP A & GROUP B & p value \\
\hline $\begin{array}{l}\text { MEAN NEONATAL BIRTH } \\
\text { WEIGHT (KG) }\end{array}$ & $2.66 \pm 0.23$ & $2.73 \pm 0.23$ & 0.33 \\
\hline MEAN APGAR SCORE & $7.28 \pm 1.37$ & $8.54 \pm 1.44$ & 0.70 \\
\hline NICU ADMISSION & 3 & 4 & 0.80 \\
\hline PERINATAL MORALITIES & 0 & 0 & - \\
\hline
\end{tabular}


Fig.1 Distribution of cases according to Bishop's score at time of admission
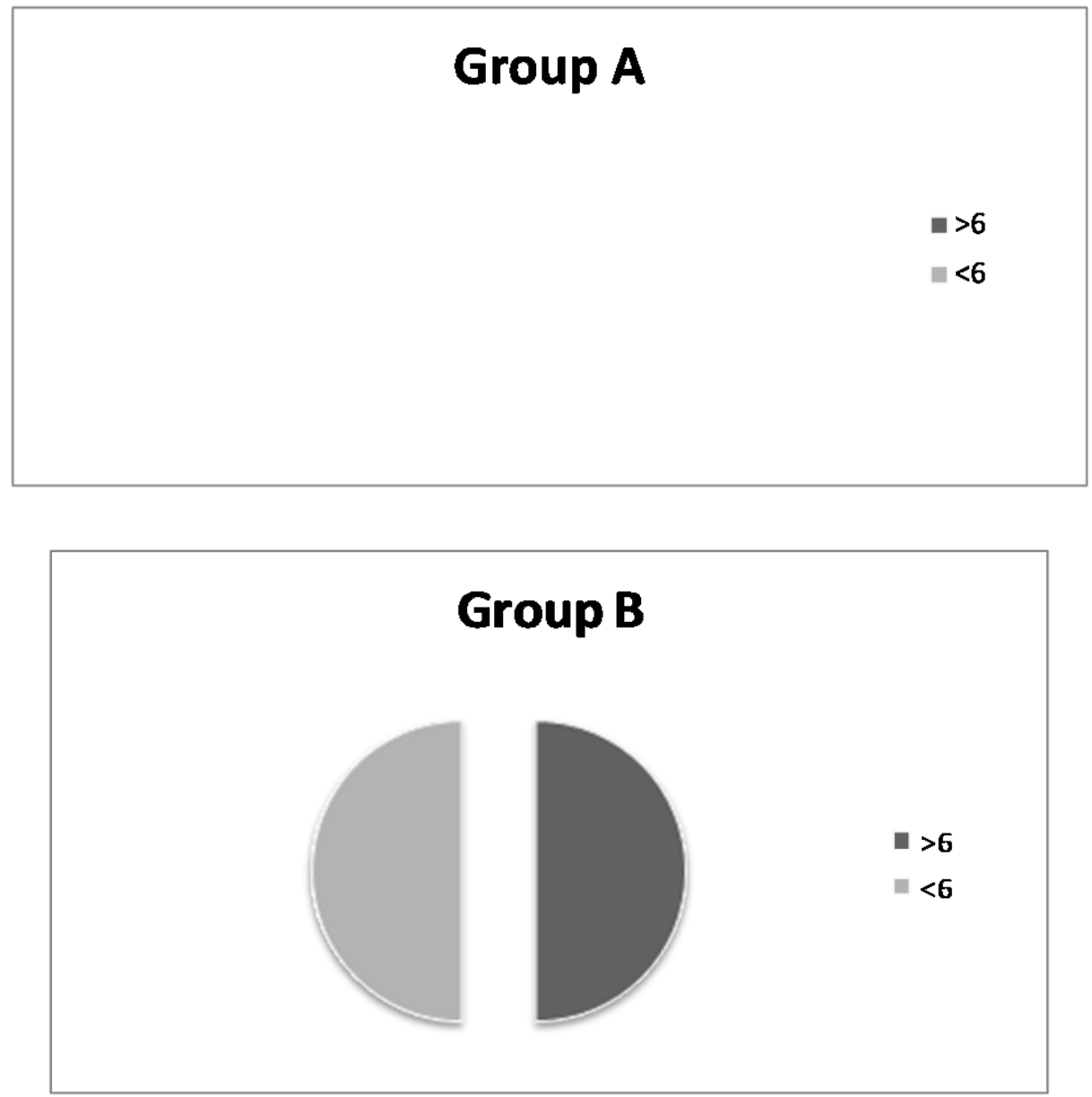

Fig.2 Distribution of cases according to modified Bromage score in both the groups

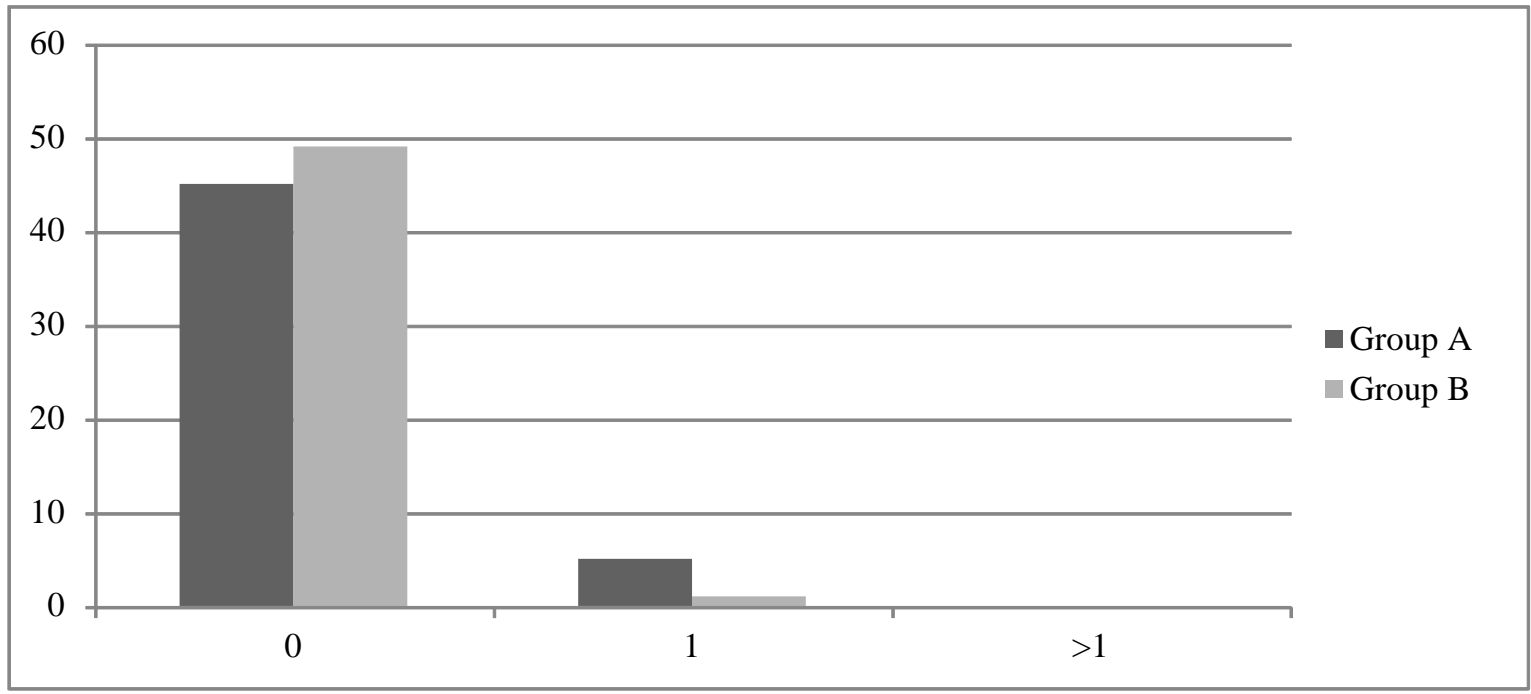


Fig.3 Distribution of cases according to maternal satisfactions
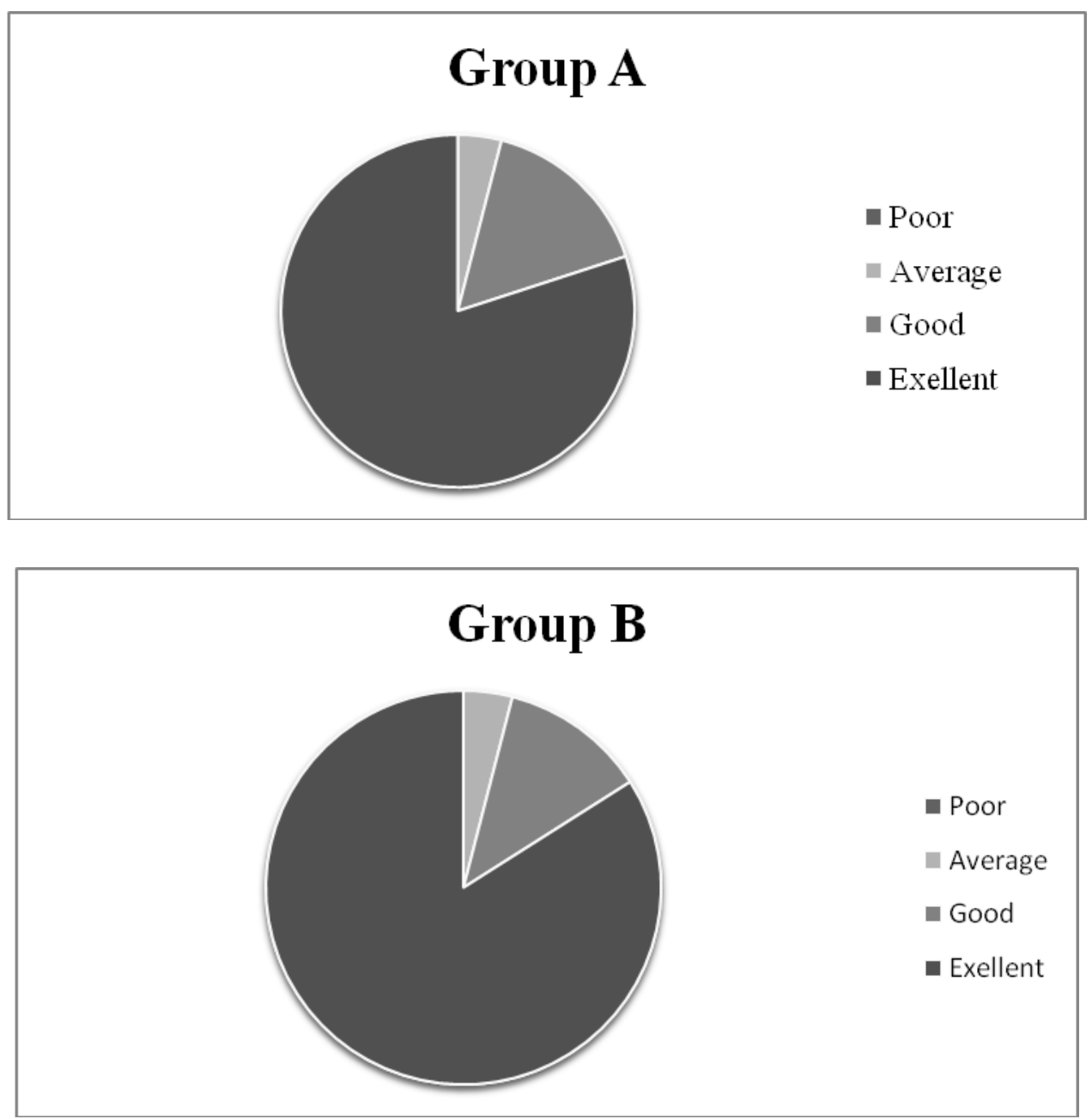

Fig.4 Distribution of cases according to VAPS score in both groups

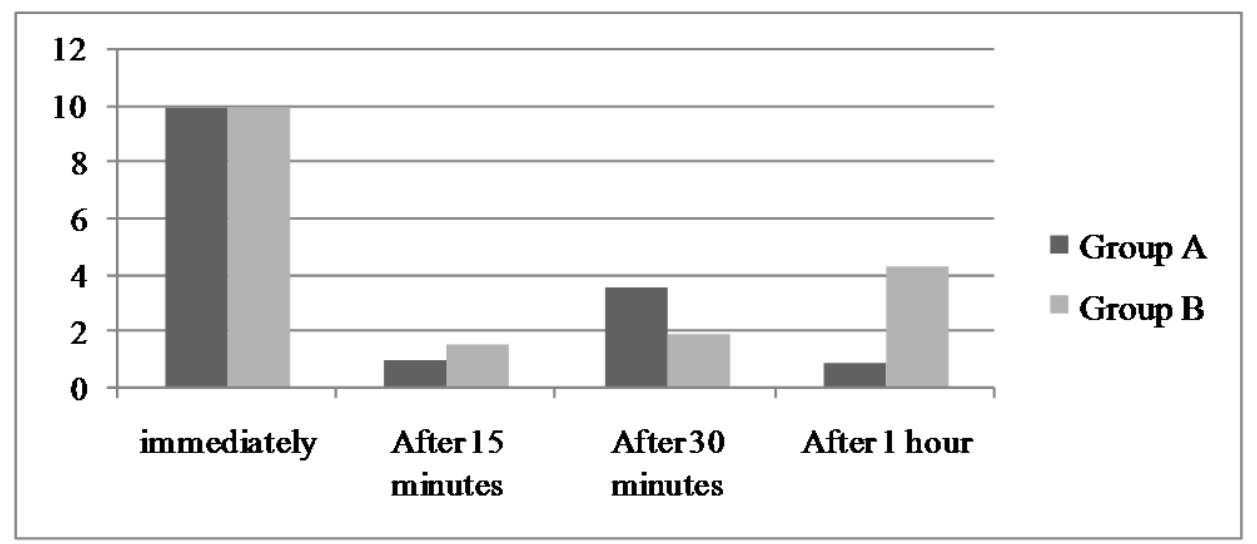


Fig.5 Distribution of cases according to side effects in both groups

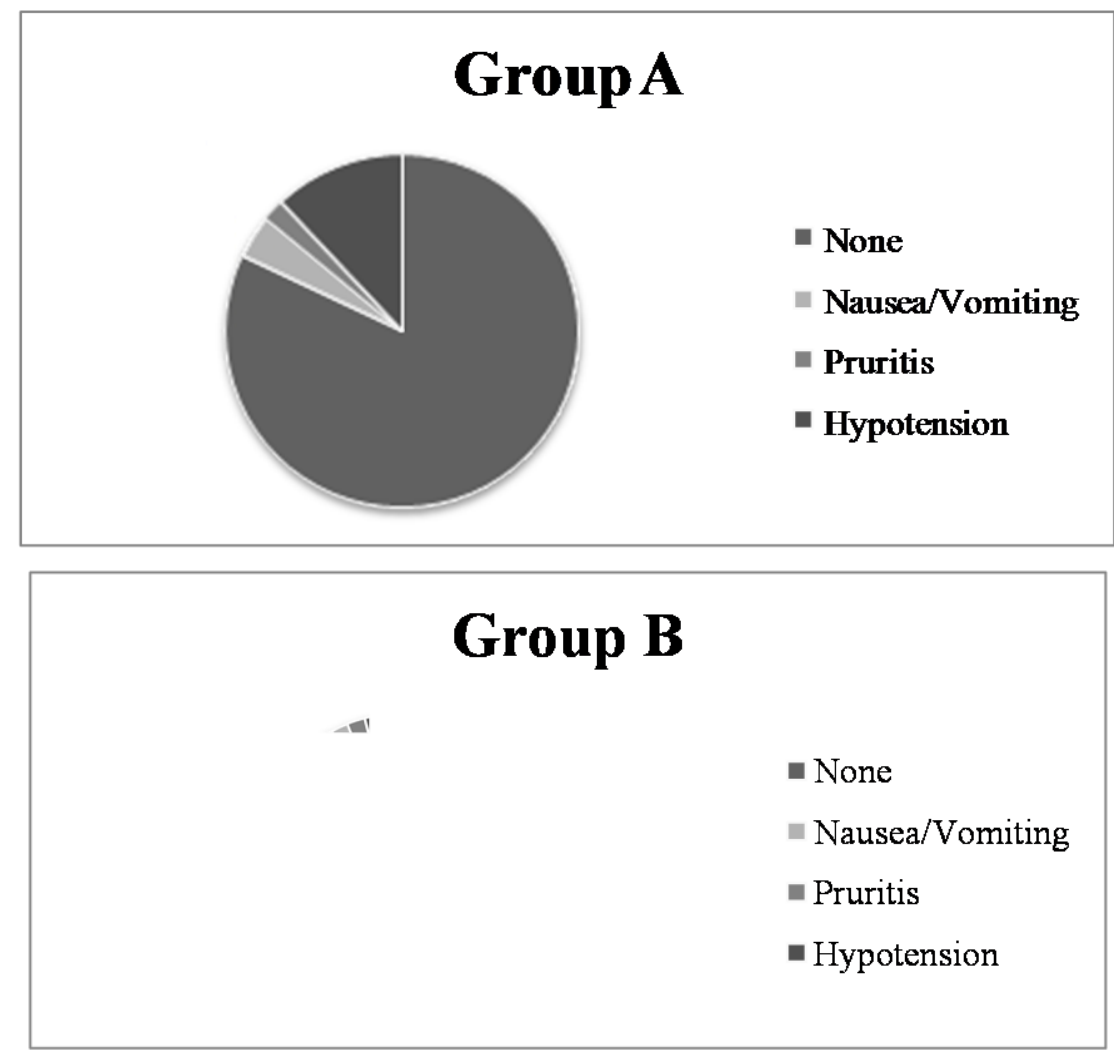

In the last decade, two long acting local anaesthetic agents, ropivacaine and levobupivacaine have challenged the position of bupivacaine as the drug of choice for labour analgesia. These agents which exist purely in Lisomeric form may be suitable alternatives to bupivacaine for cardiac and neurological toxicity compared with bupivacaine. In addition, when compared in equal concentration in labour, ropivacaine produces less motor block than bupivacaine, when combined with fentanyl or sufentanyl. ${ }^{(3)}$

Levobupivacaine and ropivacaine are the most commonly used local anesthetics for the purpose of epidural analgesia during labour. Previous studies showed ropivacaine to be significantly less potent than levobupivacaine when these drugs were used for epidural analgesia during labour. However, several recent studies showed ropivacaine and bupivacaine to be equipotent at clinically relevant doses ${ }^{(4)}$. Likewise in our study it was found that both Levobupivacaine and ropivacaine have equal potency as the mean duration between time of admission and delivery was same, the time required for the onset of analgesia was almost same, mean dose of the two agents as well as mean number of boluses required was same for the two drugs without any statistically significant difference among the two groups.
In various studies ${ }^{(5)}$, it was concluded that bupivacaine, levobupivacaine and ropivacaine seems to be almost similar in regard of motor blockage, mode of delivery and duration of labour, similar conclusion was derived from our study. In the study, there was no stastically significant difference in the mode of delivery among the two groups as supported by the previous Bellin et al ${ }^{9} \&$ Li Zhong et al.. ${ }^{(6)}$

No significant difference was detected in the neonatal outcome in both groups in our study as supported by a study conducted by Burke et al, $1999^{(7)}$.

There was no significant difference in the side effects of the two groups.

All parturients were interviewed about acceptance and views on labour technique. We found that maternal level of satisfaction was excellent to good in about $99 \%$ cases in both the groups.

Further studies with larger number of participants may demonstrate differences, If any, between the two groups.

In our study, it was concluded that both levobupivacaine and ropivacaine have equal efficacy and safety for labour 
analgesia and both of them have comparable maternal and perinatal outcome.

\section{References}

1. Capogna G, Celleno D, Fusco P, et al. Relative potency of bupivacaine ropivacaine for analgesia in labor. B J Anaesth 1999; 82: 371-3.

2. Polley LS, Columb MO, Naughton NN, et al. Relative analgesia potencies of ropivacaine and bupivacaine for epidural analgesia in labor: implications for therapeutic indexes. T. of Anaesthesiology 1999; 69: 794-801.

3. Owen MD, Thomas JA, Smith T, et al. Ropivacaine $0.075 \%$ and bupivacaine $0.075 \%$ with fentanyl 2 $\mu \mathrm{g} / \mathrm{ml}$ are equivalent for labor epidural analgesia. Anesth Analg 2002; 94: 179-801.
4. Owen MD, D'Angelo R, Gerancher JC, et al. $0.125 \%$ Ropivacaine is similar to $0.125 \%$ bupivacaine for labor analgesia using patient-controlled epidural infusion. Anesth Analg 1998; 86: 527-31.

5. Sah N, Vallejo M, Phelps A, Finegold H, Mandell G, Ramanathan S: Efficacy of ropivacaine, bupivacaine, and Levobupivacaine for labor epidural analgesia. JClinAnesth 2007; 19(3):214-7.

6. Beilin Y, Guinn NR, Bernstein HH, Zahn J, Hossain S, Bodian CA: Local anesthetics and mode of delivery: bupivacaine versus ropivacaine versus levobupivacaine. Anesth Analg 2007; 105 (3): 756-63.

7. Burke D, Henderson DJ, Simpson AM, et al: Comparision of $0.25 \%$ S(-)-bupivacaine with $0.25 \%$ RS- bupivacaine for epidural analgesia in labor. Br J Anesth 1999, 83:750-5

\section{How to cite this article:}

Meenal Jain, Richa Singh and Archana Agarwal. 2019. A Comparative Study for Efficacy of Levobupivacaine and Ropivacaine on Labor Analgesia. Int.J.Curr.Res.Aca.Rev. 7(3), 75-80.

doi: https://doi.org/10.20546/ijcrar.2019.703.006 